\title{
Investigation of Microwave Drying Characteristics of Carrot Slices
}

\author{
Dinçer Akal, Kamil Kahveci \\ Trakya University \\ Mechanical Engineering Department, Trakya University, 22180 Edirne, Turkey \\ dincerakal@trakya.edu.tr; kamilk@trakya.edu.tr
}

\begin{abstract}
In this study, drying behaviour of carrot slices in a microwave dryer was investigated experimentally and drying was modelled by the semi-empirical Page model. Experimental study was conducted for two different slice thicknesses (1 cm and $2 \mathrm{~cm})$ and three different microwave power levels $(350 \mathrm{~W}, 460 \mathrm{~W}$, and $600 \mathrm{~W})$. During experiments, weight of the carrot samples were recorded at regular intervals of 15s. Experimental results show that drying rate increases considerably with an increase in the microwave power level. The experimental results also show that the effect of carrot thickness on drying rate shows a decrease with an increase in the microwave power level. Finally experimental results indicate that energy consumption during drying shows a decrease by an increase in the microwave power level. The statistical analyses results indicate that the semi-empirical Page model can be used to define the microwave drying behaviour of carrot slices.
\end{abstract}

Keywords: Microwave drying, carrot, moisture content, Page model.

\section{Introduction}

Drying is one of the most widely used techniques in long-term preservation of food materials. The moisture inside the material is the main cause of the physical and chemical changes and the drying process decreases the amount of moisture of food product to a certain degree.

There are many different techniques used in drying of food materials. One of the mostly used drying method is convective drying. In this method hot air is sent into a drying chamber that contains food materials. In this drying method, drying occurs by molecular diffusion of moisture as a result of concentration difference between the drying air and food material. Moisture removal by diffusion takes relatively a long period of time. Drying rate increases with an increase in the drying air temperature as a result of increase in diffusion coefficient and decrease in moisture concentration of the drying air. Therefore, food material generally exposes to high temperatures, which has a negative effect on the quality of food materials. Another disadvantage of hot air drying is high energy cost due to the long drying times. As a result, other drying methods such as microwave drying have become popular in recent years. In microwave drying, thermal energy is generated inside the food material by transformation of electromagnetic energy into molecular kinetic energy. As a result, temperature reaches to the evaporation temperature in relatively short time and liquid moisture is vaporized. Due to vaporization, pressure inside the material increases and moisture is removed due to the difference in pressure between inside and outside of the food material. Therefore, microwave drying is much faster, energy consumption during drying is lower and exposure time of food materials to high temperatures is shorter. Microwave drying also provides more uniform drying.

There are a number of studies in the literature on investigation of microwave drying behavior of food materials. Microwave drying kinetics of apple and tomato slices was investigated by experimentally and theoretically Çelen and Kahveci $[1,2]$. Their experimental results show that the drying time, energy consumption decrease considerably with an increase of microwave power. Microwave and hot-air drying characteristics of banana slices were studied by Garcia et al. [3]. They found that drying time in the microwave dryer is seventeen to twenty times less than in the hot-air drier. A study on energy consumption in microwave drying of garlic cloves was conducted by Sharma and Prasad [4]. They observed that $70 \%$ energy saving is obtained by microwave drying instead of convective hot-air drying. Microwave drying characteristics of pretreated green peas was examined by Priyadarshini and Mishra [5]. The green peas were treated with citric acid solutions and blanched with hot water. Their result show that blanched samples dry faster than those in other pretreatments. Their results also show that drying rate does not show a constant rate drying period and drying process takes place in the falling rate period. Microwave drying kinetics of okra was investigated by Dadalı et al. [6]. Their results 
indicate that drying time decreases considerably with an increase in microwave power level and with a decrease in mass of sample. They also observed that drying of okra takes place both in the constant rate and falling rate periods. Microwave drying behavior of onions with different varieties was studied by Laguerre et al. [7]. They observed that maximum drying rate and drying duration is affected by the variety but it is influential only in the early stage of drying. Microwave drying characteristics of spinach was studied by Ozkan et al. [8]. Their results show that average drying rate is between 0.045 $\mathrm{kg} / \mathrm{kgmin}$ to $0.802 \mathrm{~kg} / \mathrm{kgmin}$ for microwave power ranging between $90 \mathrm{~W}$ and $1000 \mathrm{~W}$. Microwave drying behavior of white beans was investigated by Adu and Otten [9]. Their results indicate that seed temperature increases rapidly during the initial stages of drying to a maximum value and begins to decrease gradually during the latter stages of drying. Microwave drying characteristics of sardine fish was studied by Darvishi et al. [10]. Their results show that increasing microwave power from $200 \mathrm{~W}$ to $500 \mathrm{~W}$ shortens drying time up to $51 \%$.

In this study, microwave drying characteristics of carrot slices were determined experimentally and drying was modelled by the semi-empirical Page model.

\section{Materials and Method}

In this study, carrot was used to determine the experimental microwave drying behavior. For this purpose, carrot samples provided from local market were divided into pieces with different thicknesses. Two different thickness values were selected: 1 and $2 \mathrm{~cm}$. The mean diameter and weight of the carrot slices used in the experiments were $3 \mathrm{~cm}$ and $30 \pm 2 \mathrm{~g}$, respectively.

Drying experiments were carried out in a microwave oven. The schematic view of the experimental setup used in microwave drying is seen in Figure 1. Experimental setup consists of a microwave oven of $2450 \mathrm{MHz}$ frequency, $700 \mathrm{~W}$ power and of $20 \mathrm{~L}$ capacity, a digital scale of $\pm 0.001 \mathrm{~g}$ and a capacity of $620 \mathrm{~g}$ and a computer. The weight of the carrot slices during the drying process was measured by a digital scale at every $15 \mathrm{~s}$ and the results were recorded on the computer. An energy counter was also used to measure the energy consumption during microwave drying.

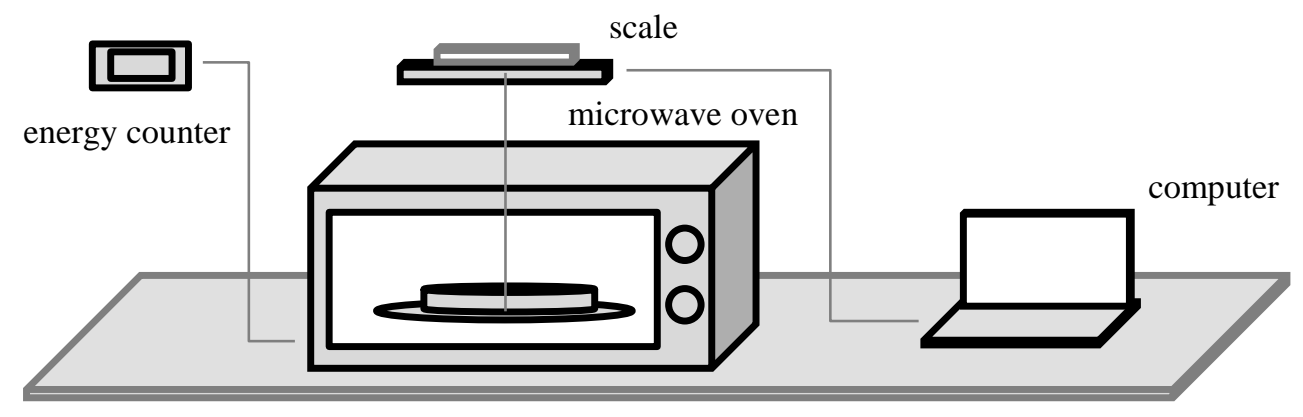

Fig. 1: Schematic view of the experimental setup.

\section{Results and Discussion}

Drying experiments were conducted for two different carrot thicknesses of $1 \mathrm{~cm}$ and $2 \mathrm{~cm}$ and three different microwave power levels of $350 \mathrm{~W}, 460 \mathrm{~W}, 600 \mathrm{~W}$.

Moisture ratio is defined as:

$$
m r=\frac{m}{m_{o}}
$$

where $m$ and $m_{o}$ are the instantaneous and initial mass of the material, respectively.

Drying behaviour was also modeled in this study by the semi-empirical Page model defined as:

$$
m r=\exp \left(-k t^{n}\right)
$$

where $\mathrm{t}$ is the drying time and $\mathrm{k}$ and $\mathrm{n}$ are drying constants. 
Experimental drying data and drying curves based on the Page model are shown in Figures 2-4 for different values of carrot thicknesses and microwave power levels. Drying was ceased at a certain level of moisture content because darkening was seen to develop in the carrot surfaces due to the burning. As it can be seen from the figures that drying rate is low at the beginning of drying. There is a heating stage at the beginning of drying and temperature of the moisture first increases until the evaporation temperature, Therefore, drying rate is low in this stage. After this stage, drying rate shows an increase due to the increase in pressure inside the material as a result of evaporation. Furthermore, the moisture content of the carrot slices is high at this relatively early stage of the drying which results in a higher absorption of microwave power and higher drying rates. As the drying progress, the loss of moisture in the food product causes a decrease in the absorption of microwave power. This results in a decrease in the drying rate as it can be seen in Figures 2-4. As the thickness of the carrot slices is increased, the drying rate decreases. The effect of thickness on drying rate decreases with an increase in the microwave power. Therefore, microwave power can be said to be the most effective factor in drying. Drying rates shows a considerable increase with an increase in microwave output power. Increasing microwave power level from $350 \mathrm{~W}$ to $600 \mathrm{~W}$ decreases the drying time $48 \%$.

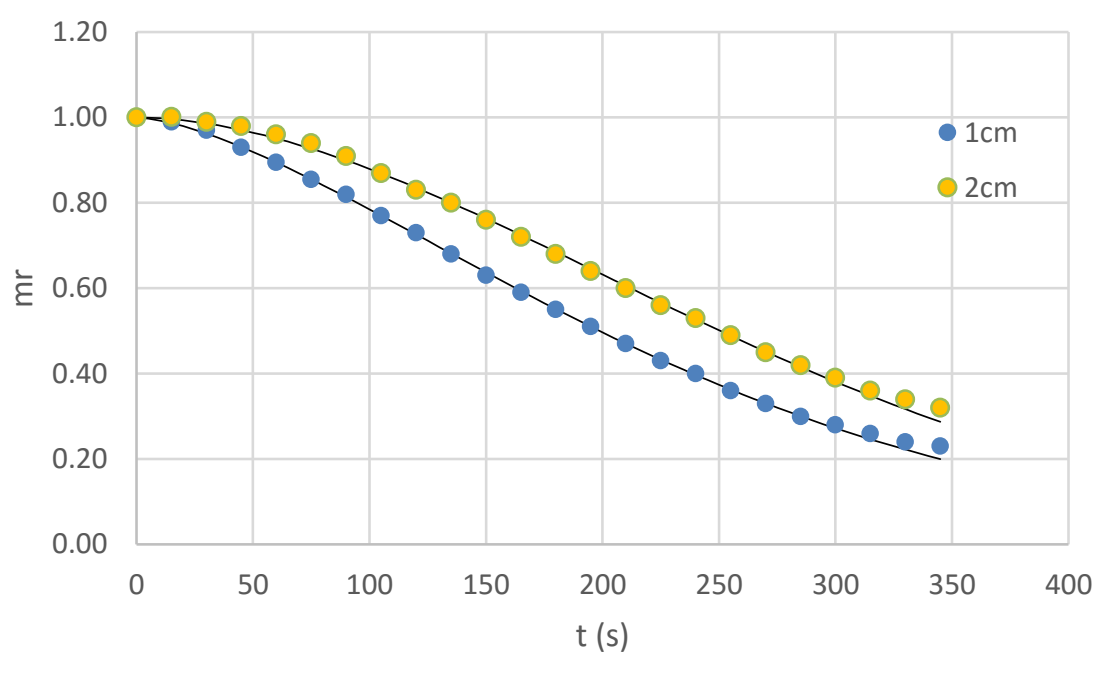

Fig. 2: Drying curves of the carrot slices for microwave power level of $350 \mathrm{~W}$.

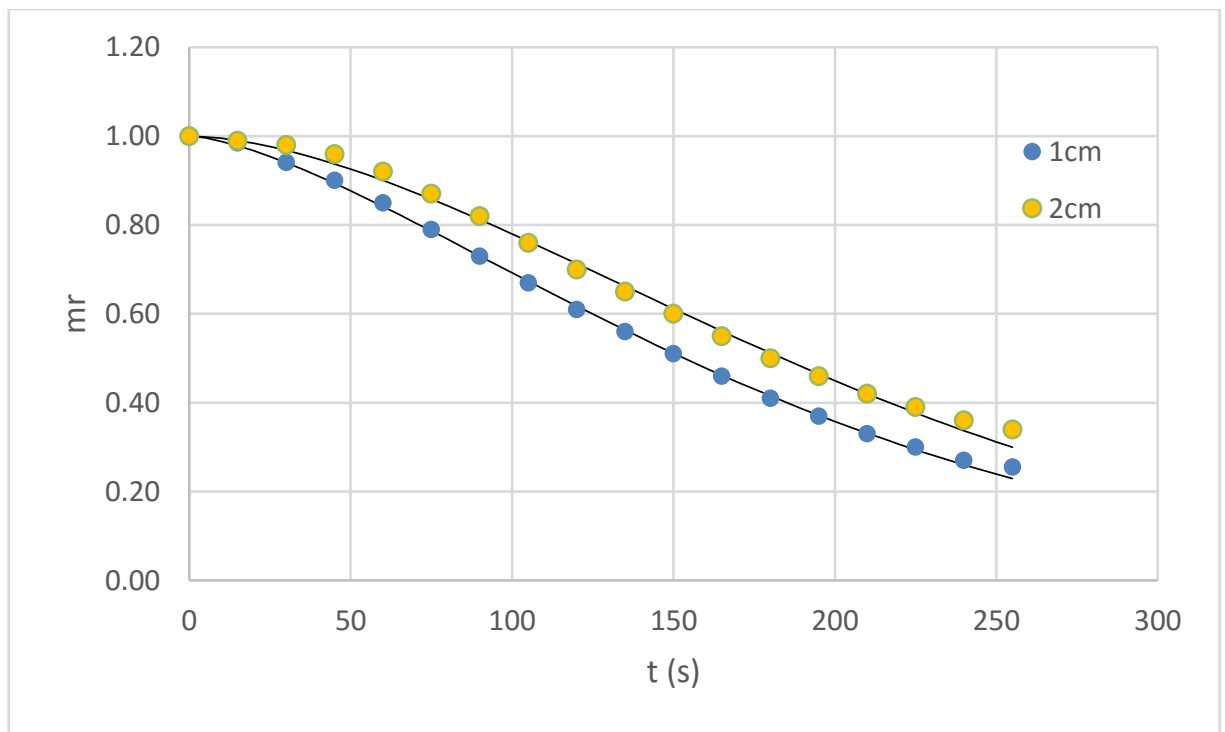

Fig. 3: Drying curves of the carrot slices for microwave power level of $460 \mathrm{~W}$. 


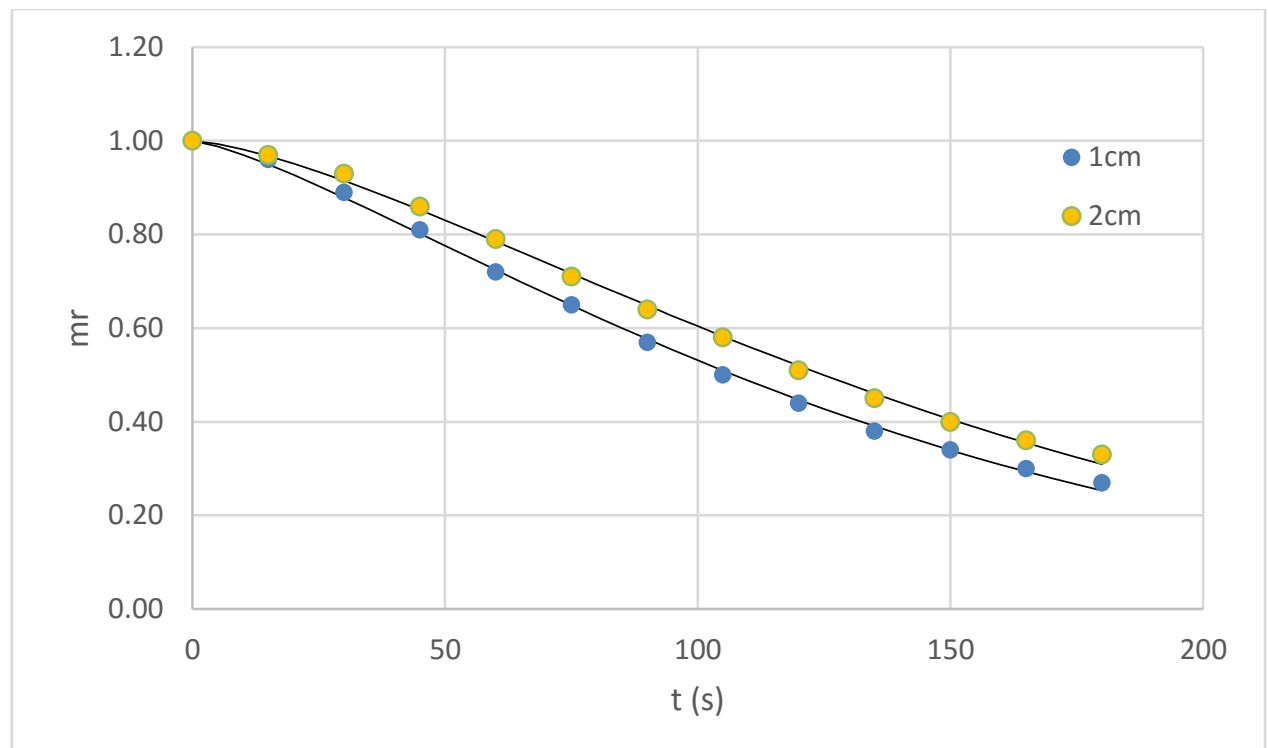

Fig. 4: Drying curves of the carrot slices for microwave power level of $600 \mathrm{~W}$.

Energy consumption during microwave drying is seen in Table 1 for different microwave power levels. Energy consumption takes lower values with an increase in microwave power level as a result of decrease in drying time. Energy consumption decreases approximately $\% 10$ when microwave power is increase from $350 \mathrm{~W}$ to $600 \mathrm{~W}$.

Table 1: Energy consumption during microwave drying.

\begin{tabular}{|c|c|}
\hline microwave power & energy consumption \\
\hline $350 \mathrm{~W}$ & $335 \mathrm{Wh}$ \\
\hline $460 \mathrm{~W}$ & $326 \mathrm{Wh}$ \\
\hline $600 \mathrm{~W}$ & $300 \mathrm{Wh}$ \\
\hline
\end{tabular}

The modelling results of the Page model are shown in Table 2. The RMSE is the root mean square error. From the results of the RMSE, it can be concluded that the microwave drying behaviour of carrot slices can be adequately defined by the Page model.

Table 2: Coefficients of the Page model.

\begin{tabular}{|c|c|c|c|c|}
\hline microwave power & thickness & $\left.\mathrm{k}^{-1}\right)$ & $\mathrm{n}$ & RMSE \\
\hline \multirow{2}{*}{$350 \mathrm{~W}$} & $1 \mathrm{~cm}$ & $2.1217 \mathrm{E}-04$ & 1.5290 & $1.6839 \mathrm{E}-02$ \\
\cline { 2 - 5 } & $2 \mathrm{~cm}$ & $2.7464 \mathrm{E}-05$ & 1.8352 & $2.8109 \mathrm{E}-02$ \\
\hline \multirow{2}{*}{$460 \mathrm{~W}$} & $1 \mathrm{~cm}$ & $3.9896 \mathrm{E}-04$ & 1.4824 & $2.0499 \mathrm{E}-02$ \\
\cline { 2 - 5 } & $2 \mathrm{~cm}$ & $1.0567 \mathrm{E}-04$ & 1.6858 & $5.1851 \mathrm{E}-02$ \\
\hline \multirow{2}{*}{$600 \mathrm{~W}$} & $1 \mathrm{~cm}$ & $1.4551 \mathrm{E}-03$ & 1.3193 & $3.0633 \mathrm{E}-02$ \\
\cline { 2 - 5 } & $2 \mathrm{~cm}$ & $6.7222 \mathrm{E}-04$ & 1.4375 & $3.3494 \mathrm{E}-02$ \\
\hline
\end{tabular}

An uncertainty analysis was also carried out to obtain the uncertainty in the experimental weight measurement. The uncertainty due to the weight measurement can be calculated by the following relation [11]:

$$
W=\left[S^{2}+T^{2}+C^{2}\right]^{1 / 2}
$$

where $S$ is the uncertainty $S$ is the uncertainty due to the scale accuracy, $T$ is the uncertainty due to the drying time, and $\mathrm{C}$ is the uncertainty due to the effect of moist-air currents inside the microwave oven. The uncertainties were given in 
Table 3. The total uncertainty in weight measurements was calculated approximately as $\pm 0.3 \mathrm{~g}$, which corresponds approximately to a $\pm 1 \%$ uncertainty.

Table 3: Experimental uncertainties in weight measurements.

\begin{tabular}{|c|c|}
\hline Scale accuracy & $\pm 0.001 \mathrm{~g}$ \\
\hline Drying time & $\pm 0.01 \mathrm{~g}$ \\
\hline Moist-air currents & $\pm 0.3 \mathrm{~g}$ \\
\hline
\end{tabular}

\section{Conclusion}

Microwave drying behaviour of carrot slices was investigated experimentally for different values of microwave power and carrot thickness, and drying was modelled by the semi-empirical Page model. Concluding remarks are as follows: Drying rate increases considerably with an increase in the microwave power level. The effect of carrot thickness on drying rate shows a decrease with an increase in the microwave power level. Energy consumption during microwave drying process shows a decrease by an increase in the microwave power level. The semi-empirical Page model can be used to define the microwave drying behaviour of carrot slices. The uncertainty in experimental weight measurements is approximately $\pm 1 \%$.

\section{References}

[1] S. Çelen and K. Kahveci, "Microwave drying behaviour of apple slices," in Proceedings of the Institution of Mechanical Engineers, Part E, Journal of Process Mechanical Engineering, vol. 227, no. 4, pp. 264-272, 2012.

[2] S. Çelen and K. Kahveci, "Microwave drying behaviour of tomato slices," Czech Journal of Food Sciences, vol. 31, no. 2, pp. 132-138, 2013.

[3] R. Garcia, F. Leal and C. Rolz, "Drying of bananas using microwave and air ovens," International Journal of Food Science \& Technology, vol. 23, no. 1, pp. 73-80, 1988.

[4] G. P. Sharma and S. Prasad, "Specific energy consumption in microwave drying of garlic cloves," Energy, vol. 31, pp. 1921-1926, 2006.

[5] R. N. S. Priyadarshini and A. A. Mishra, "Microwave drying characteristics of green peas and its quality evaluation," International Journal of Agriculture and Food Science Technology, vol. 4, no. 5, pp. 445-452, 2013.

[6] G. Dadal1, D. Kılıç Apar and B. Özbek, "Microwave drying kinetics of okra," Drying Technology, vol. 25, no. 5, pp. 917-924, 2007.

[7] J. C. Laguerre, V. Tauzin and E. Grenier, "Hot air and microwave drying of onions: a comparative study," Drying Technology, vol. 17, no. 7-8, pp. 1471-1480, 1999.

[8] I. A. Ozkan, B. Akbudak and N. Akbudak, "Microwave drying characteristics of spinach," Journal of Food Engineering, vol. 78, pp. 577-583, 2007.

[9] B. Adu and L. otten, "Microwave heating and mass transfer characteristics of white beans," Journal of Agricultural Engineering Research, vol. 64, pp. 71-78, 1996.

[10] H. Darvishi, M. Azadbakht, A. Rezaeiasl and A. Farhang, "Drying characteristics of sardine fish dried with microwave heating," Journal of the Saudi Society of Agricultural Sciences, vol. 12, pp. 121-127, 2013.

[11] E.K. Akpınar, "Deneysel çalışmalardaki hata analizine bir örnek: kurutma deneylerindeki hata analizi," Mühendis ve Makina, vol. 46, no. 540, pp. 41-48, 2005. 